\title{
More on Prophetic Visions and the Inner Self Helper
}

\section{To the Editor:}

I was quite interested in Dan Punzak's letter (1990), and would like to address two points that he discussed. The first is the question of whether or not guides seen by near-death experiencers (NDErs) are similar to, or the same as, Inner Self Helpers (ISHs) in persons with multiple personality disorder (MPD). The second point is why some of the predictions offered by NDE guides do not come true. My ideas on this subject come from being an NDEr, a therapist who specializes in working with persons with MPD, and a fairly "normal" (I think) individual who is aware of my own multiplicity.

I do, indeed, think that the Inner Self Helper found in persons with MPD may well be related to, or the same as, the guides experienced by NDErs. I am among the group of therapists, alluded to by Punzak, who believe that all of us have ISHs. In fact, my own beliefs go even further, in that I also believe that all of us are probably "multiple," but that few of us have access to that information as readily as does someone who is clinically diagnosed as having MPD.

My own sense is that "spirits," such as ISHs and guides, exist in "chains of command," with some of the "lower" ones being, perhaps, parts of the person's own unconscious, while others may be largely outside of the person's body, but able to come into the body for certain purposes, and still others, the highest ones, may never incarnate, but may, nevertheless, be able to communicate with the individual via some of the lower entities.

In my experience with persons with MPD, they often have several ISHs, some of whom will refer to themselves as part of the person's consciousness, while others describe themselves as being spirits or guides who are around to help the individual but are not part of the individual. I know of cases in which the therapist can contact a lower ISH and ask for information, and the ISH will wait a while before responding, listening to a response from "higher up" and then relaying the information. I do not know where to place NDE guides in this chain of command, but it does make sense to me that both ISHs and NDE guides are part of the same basic genre.

As for inaccurate predictions, I have several possible explanations as to why these occur. I want to preface what I say by adding that I am much more familiar with predictions on a personal as opposed to a global level, so I'm not sure how much of the information will generalize. 
First, in line with what Punzak was suggesting, I am quite certain that messages from ISHs and/or other types of spirit guides can be unwittingly and unknowingly distorted by the individual receiving them. One thing that frequently causes this distortion is that secondary personalities, including ISHs, often "blend" with the consciousness of the host personality or of other alter personalities, to a greater or lesser extent, so that the secondary personality may not be present in a "pure" form. In this situation, messages from an ISH can be distorted, unknown to any, except, presumably, the ISH itself.

As an aside, I suspect that it may be partially this phenomenon that accounts for the widely divergent concepts of a Supreme Being. I believe that divine revelations get filtered through individual and perhaps even cultural consciousnesses, and then become consolidated into a particular myth or belief, thus giving us almost as many concepts of God as there are individuals.

The second possibility for inaccurate predictions, which was also mentioned by Punzak, is that ISHs or other types of spirit helpers may well be able to alter the future, possibly as a result of human intervention. I know that it is fairly common for therapists to "train" ISHs, to teach them things to do that the ISH did not realize were in its capacity.

A simplistic example might be a case in which an ISH would inform the therapist that a certain alter personality was going to come out that night and attempt to take the patient's life. A possible intervention might be for the therapist to teach the ISH ways to "freeze" or immobilize the alter in question, thus preventing the predicted suicide. While this is a very direct way of working with an ISH to change the future, I also agree with Punzak's idea that more indirect intercessions such as thoughts and prayers might also be able to alter predicted future events.

A third explanation for inaccurate predictions is that it is not uncommon for ISHs and other types of spirits to communicate via symbols, metaphors, and parables. If we take these kinds of communications literally, we will obviously misunderstand their intended meaning.

The final idea I have to offer concerning inaccurate predictions came to me directly from an ISH, and was one I had not previously thought of. The ISH likened the relationship between entities like herself and humans to that between a mother and a child, and explained that mothers frequently talk to young children in very concrete, black-andwhite terms for two reasons. First, children think in concrete ways, and thus respond better if treated this way; and second, even the very best of mothers has only limited information about the world she lives in, 
and can only present things that are within the scope of her knowledge. The example given was that before it was known that the world was round, mothers taught their children that the world was flat, because that's the way they believed it to be.

The ISH went on to explain that there are many different "subworlds" that make up the totality of all that is, and that it is far too simplistic to think in terms of only two of these subworlds, our physical world and one single spirit world. Furthermore, any one ISH can give information based only on the particular worlds they intersect with, and may, in fact, have little or no awareness of any other worlds, just as many human beings have no awareness of any of the spirit worlds.

However, due to the two reasons just listed-our limited ability to understand, and incomplete and/or inaccurate knowledge on the part of the ISH-information will often be given as if it is known to be the absolute truth. Our wont as human beings is either to reject the information entirely, usually if we have no direct experience with the other worlds ourselves, or to accept it without question in its totality. This is analogous to young children who tend to accept everything their mothers tell them.

To close, I can say that being in the presence of an ISH can, indeed, give one the sense of being with a consciousness that is much more highly evolved than oneself. Also, I almost always feel that such beings have much greater wisdom about the individual in question, as well as about many other types of things, especially those of a spiritual nature, than I. However, I think that, as with any other type of information we receive, it is important to weigh input received from such beings carefully, and to remain open to additional information. Children can get themselves in trouble, and/or fail to grow and develop properly, if they adhere rigidly to things they learned from their mothers when they were two.

Susan C. Litton, Ph.D. 1834 Clairmont Decatur, GA 30033 